\title{
MAST CELL PROFILE IN LYMPH NODE DISORDERS
}

Pradeep Kumar. N. S. Ravi Shankar Pillai.

1. Professor \& HOD, Department of Pathology, SLIMS. Puducherry.

2. Associate Professor, Department of Pathology, SLIMS. Puducherry.

\section{CORRESPONDING AUTHOR}

Pradeep Kumar Narayanapa Shiroorkar, Shri Lakshminarayana Institute of Medical Sciences, Osudu, Agaram, E-mail: dr.pradeep-kumar33@yahoo.com Ph: 00919345476620

ABSTRACT: Mast cell is a unicellular endocrine organ with many compounds in it acting both in physiological and pathological conditions like inflammation, wound healing, parasitic infestations, allergic conditions and in neoplastic conditions like primary and secondary neoplasms 4, 6. Actually mast cells are present in normal lymph nodes. Its number and distribution varies in different pathological conditions of lymph node 6,9 .

This study was undertaken to identify the variation of mast cells in number and distribution in different pathological conditions of lymph node. This study was done on biopsy specimens received by the department of Pathology in our medical college. 122 biopsy specimens of different pathological conditions (neoplastic, non - neoplastic and combined lesions) were received by the department of Pathology for a period of 2 years and analyzed for mast cell variations. These variations were compared with 10 lymph nodes from cadaver.

Maximum number of mast cells were observed in chronic non specific lymphadenitis $(78.85 \pm 20.21 / 10 \mathrm{HPF})$ and in sinus histiocytosis $(78.80 \pm 28.2 / 10 \mathrm{HPF})$. Moderate increase was found in dermatopathic lymphadenitis $(50 / 10 \mathrm{HPF})$, Hodgkin's lymphoma (HL) $(45,70)$ and Metastatic lymph node (51.93 \pm 18.7$)$. Mild increase was seen in NHL $(25 \pm 12)$. This count was decreased (11.93 $\pm 5.24 / 10 \mathrm{HPF}$ ) in tuberculosis. In addition to provide diagnostic clue it also gives scope for further research.

KEY WORDS: Mast cells, Lymph nodes, Disorders

INTRODUCTION: The mast cell is popularly known as emergency kit because it secretes stores and releases many compounds necessary for the normal functions of our body like inflammation, wound healing and allergic conditions 6,8 .

Although it was identified 140 years back many things are yet to be known about it. The Mast cell stores many secrets to be revealed. Mast cells are developed from marrow stem cells and distributed all over the body in various proportions but not found in bone, cartilage and brain. It is a large cell about 140 microns in diameters contains granules filled with chemical mediators 5,6 .

Lymph nodes were selected for this study because it is involved in many pathological conditions which are a diagnostic dilemma. Mast cell study is a simple and economical method which gives an additional clue to diagnosis. Only a few studies are available on this aspect. Thus the present study was undertaken to identify the variations of mast cells in number and distribution in different pathological conditions like neoplastic and non neoplastic conditions. 
METERIALS AND METHODS: This prospective study was conducted in the department of pathology, of our college. Total 122 biopsy specimens were collected from 57 male and 65 female patients with the age distribution between 6 to 77 years. Out of 122 biopsy specimens 48 specimens were follicular hyperplasia, 11 were from lymphoma lesions, 5 were from sinus histiocytosis, 41 were from tuberculosis lesions and 15 were from secondaries in lymph node. One case was a combined lesion of Tuberculosis and metastatic and one case of dermatopathic lymphadenitis. These specimens were studied for number and distribution of Mast cell.

Clinical history, examination findings and all the investigation results were noted. Careful gross examination of lymph node specimen was performed. Tissue bits were processed after fixation in $10 \%$ formalin, embedded in paraffin wax, thin section of 3-5 microns were taken on albuminized slide, kept at $60^{\circ} \mathrm{C}$ for 30 minutes, immersed in Xylene. Those sections were stained by $\mathrm{H} \& \mathrm{E}, 1 \%$ toluidine blue and mounted.

Mast cell were identified by purple granular cytoplasm and surrounding tissue as blue color. The section was examined in 400X magnification, and numbers of mast cells were counted for 10 non overlapping high power fields. The distribution of mast cells and state of granulation was also observed. Those variations were compared to 10 lymph nodes dissected from cadaver and processed as usual. The results were analyzed with the available data in comparison with the other studies.

RESULTS: The present study of Mast cell profile in lymph node disorders consists of 122 biopsy specimens received at department of Pathology. Alteration of mast cells in various disorders was studied.

10 Lymph nodes from cadaver was dissected, processed as usual. It was stained with $\mathrm{H}$ \& E, 1\% Toluidine blue. The mast cell count was $18 \pm 8$ per $10 \mathrm{HPF}$. They were distributed in medulla, para cortical area, capsule and interfollicular area (Fig 2A). These lymph nodes were normal histologically.

Out of 122 cases 48 were follicular hyperplasia, 5 cases were sinus histiocytosis, 41 cases were tuberculosis, 11 cases were lymphoma and 15 cases were secondaries in lymph nodes. One case was combined lesion of tuberculosis and metastasis and one case was dermatopathic lymphadenitis.

There were 57 male and 65 female patients. The age distribution was between 6 to 77 years.

\section{NON NEOPLASTIC DISORDERS}

\section{FOLLICULAR HYPERPLASIA}

Forty eight cases were studied. The Mast cell counts were ranged from 59 to 99 / 10 HPF with a mean of 78.85/10 HPF. They were distributed predominantly in the parafollicular area. No mast cells were seen within the follicles (Fig $3 \mathrm{~A}, \mathrm{~B}$ ).

\section{SINUS HISTIOCYTOSIS}

Five cases were studied. The mast cell counts varied from 47 to 109 cells / $10 \mathrm{HPF}$ with a mean of 78.80/ 10 HPF. These mast cells were distributed predominantly in the vicinity of sinuses (Fig 4).

\section{DERMATOPATHIC LYMPHADENITIS}

One case was studied and 50 mast cells / 10 HPF were found. It was distributed in the pericapsular and parafollicular areas predominantly (Fig 10). 


\section{TUBERCULOUS LYMPHADENITIS}

Forty one cases were studied. The mast cell counts were 8 to 16 /10HPF and the mean counts were 11.93/10HPF. These cells were distributed around granuloma and not inside the granuloma. Even sub capsular mast cells were found, they were comparatively less than follicular hyperplasia (Fig 5).

\section{NEOPLASTIC DISORDERS}

\section{NON HODGKIN'S LYMPHOMA}

There were 9 cases of NHL. Two Cases were low grade, 2 were high grade and 5 cases were intermediate grade lymphoma. The mast cell counts were ranged from 13 to 38 with average of 24.89 /HPF. No significant difference was observed between different types of NHL. The distribution of mast cells was uniform (Fig 6).

\section{HODGKIN'S LYMPHOMA}

There were 2 Hodgkin's Lymphoma and the mast cell count were $45 \& 70$ with a mean of 57.5 / 10 HPF. These cells were distributed randomly in capsule and sinus (Fig 7).

\section{METASTATIC LESION}

Fifteen cases were studied. The mast cell count was ranged from 33 to 71 with a mean of 51.93/ 10 HPF. They were distributed predominantly around the edge of tumor and rare within the tumor. It was observed that there was much variation in the mast cell count in different metastatic lesions (Fig 8).

\section{COMBINED LESION}

One case of metastatic lymph node with tuberculosis was studied. The mast cell count was 16 cells/ $10 \mathrm{HPF}$, predominantly around malignant cells and rare around granuloma (Fig 9).

DISCUSSION: The present study was undertaken to identify variation in mast cell in various pathological conditions of lymph node. As mast cell is a unicellular endocrine organ with many compounds in its cytoplasm, act both under physiological and pathological conditions. It is altered in different pathological conditions ${ }^{3,6}$.

Lymph node is selected because it is involved in many pathological conditions which have diagnostic problems. Mast cell study is a simple and economical method which gives an additional clue for diagnosis. Only few studies are available in this aspect.

Lymph nodes from cadaver were studied for count and distribution of mast cells. The $\mathrm{H}$ \&E Stain of lymph nodes was normal histologically. Significant increase in number of mast cells was observed in follicular hyperplasia (average $78.85 \pm 20.21 / 10 \mathrm{HPF}$ ). Similar increase was also seen in sinus histiocytosis (average $78.8 \pm 28.2$ / $10 \mathrm{HPF}$ ). In dermatopathic lymphadenitis the count was 50 / 10 HPF i.e. moderate increased. In tubercular lymphadenitis the mean count were $11.93 \pm 5.24$ / $10 \mathrm{HPF} \&$ it is less than the control. The findings were in consistent with literature $3,6,10,11$.

In NHL the average count was $24.89 \pm 11.22$ / $10 \mathrm{HPF}$. There was a moderate increase in the counts and not much variation in different types of NHL. In Hodgkin's lymphoma the average count was $57.5(45,70) / 10 \mathrm{HPF}$. It was more than NHL. In metastatic deposits, the average count was $51.93 \pm 18.7$ / 10 HPF. The cells were more around metastatic deposits. It may 
be due to mast cell secret substance to detoxify tumor products. These studies were also similar to available literature. 1, 2, 6, 7,12.

In combined lesion, the count was 16/10 HPF. But there were more cells around metastatic deposits, not around granuloma. It indicates that mast cells increases in metastatic lesion and decreases in granulomas. 5,8 . We can compare variations of mast cell distribution in different diseases in a single slide. There is no comparative literature for it.

CONCLUSIONS: One hundred twenty two Cases of lymph nodes were studied for mast cell number and distribution, (95 non neoplastic, 26 neoplastic and 1 combined lesion). The mast cells were counted for $10 \mathrm{HPF}$ and analyzed with cadaver lymph node.

Maximum number of mast cells was seen in chronic non specific Lymphadenitis (78.85 $\pm 20.21 / \mathrm{HPF})$ and sinus histiocytosis $(78.8 \pm 28.20 \mathrm{HPF})$. Moderate increase was seen in dermatopathic lymphadenitis (50/ $10 \mathrm{HPF}$ ) and reduced in tuberculosis (11.93 $\pm 5.24 / 10 \mathrm{HPF})$.

In metastatic deposits, mast cell count was increased (51.93 $\pm 18.7 / 10 \mathrm{HPF}$ ). It was also increased both in NHL and HL. But more increase was seen in HL (57.5 / 10 HPF) than NHL $(24.89 \pm 11.22 / 10 \mathrm{HPF})$

In combined lesion, mast cell count was increased around metastatic deposits but decreased around tuberculous granuloma.

There was a definite alteration of mast cells in different diseases of lymph node. In addition to providing diagnostic clue, it also gives scope for further research.

\section{REFERENCES:}

1. Croker, J., and P.J. Smith. : A quantitative study of mast cell in Hodgkin's disease. J. Clin. Pathol. 1984; 37:519 - 522.

2. Croker, J., and P.J. Smith. : Mast cells in Non Hodgkin's lymphomas: A quantitative study. J. Clin. Pathol. 1989; 470 (letter to the editor)

3. Cree, I. A., Cogtrills, and Swanson beak. : Mast cells in the skin lesion of leprosy. Synopsis of papers J. Pathol. 158: 338, 1989.

4. Dolton, R. , et al. : Mast cell leukemia: evidence of bone marrow origin of the pathological clone. Br. J. Haematol. 64: 397 - 406, 1986.

5. Elizabeth, W. Smith, William, B. Atkinson: Simple procedure for identification and rapid counting of mast cells in tissue section. Science. 1956: 123:941.

6. Hans Selye,: The Mast cells. 5th Ed., Butterworth's publication, 1965.

7. Henry, M, Bovers, et al: Number of Mast cells in the Axillary lymph nodes of breast cancer patients. Cancer 1979; 43: 568.

8. Hoggate, S. T.: Basophil, Polymorphos and Mast cells. Oxford test book of Pathology. Vol 1 P 332. Oxford University press 1992.

9. Joseph Janes, M.D., John R. Mc Donald, M.D.: Mast cells: their distribution in various human Tissues. Arch Pathology. 1989; 45:622.

10. Julie crow et al: Mast cells in reactive lymph nodes. J Pathol. 1989; 45: 622.

11. Sheffield, D.N., and Mitchell, B, Corrin: Mast cells in developing epithelioid cell granuloma. Synopsis of papers. J Pathol 1989; 356.

12. Veena K, Sharma et al: Mast cell reactivity in lymphoma: A preliminary communication. Indian J Cancer 1992; $29: 61$ 


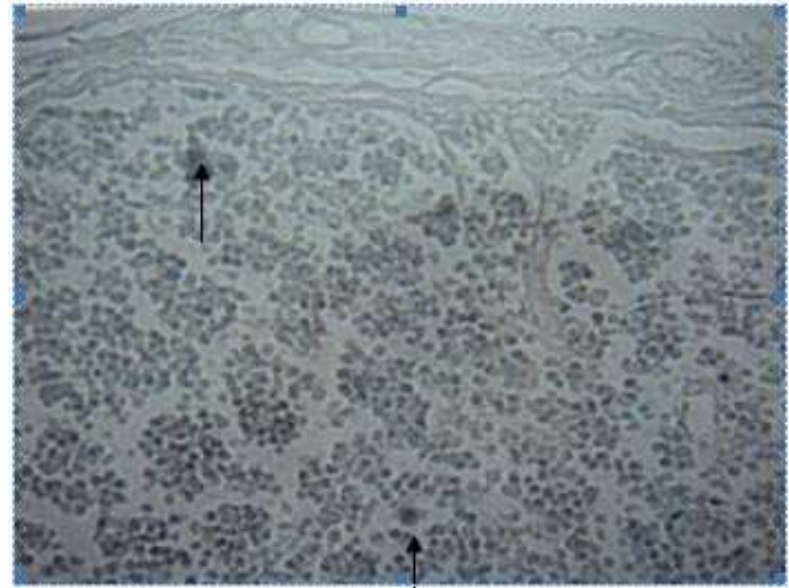

Fig. 2A. Photomicrograph Showing Mast Cells (MCs) seen in the entire field
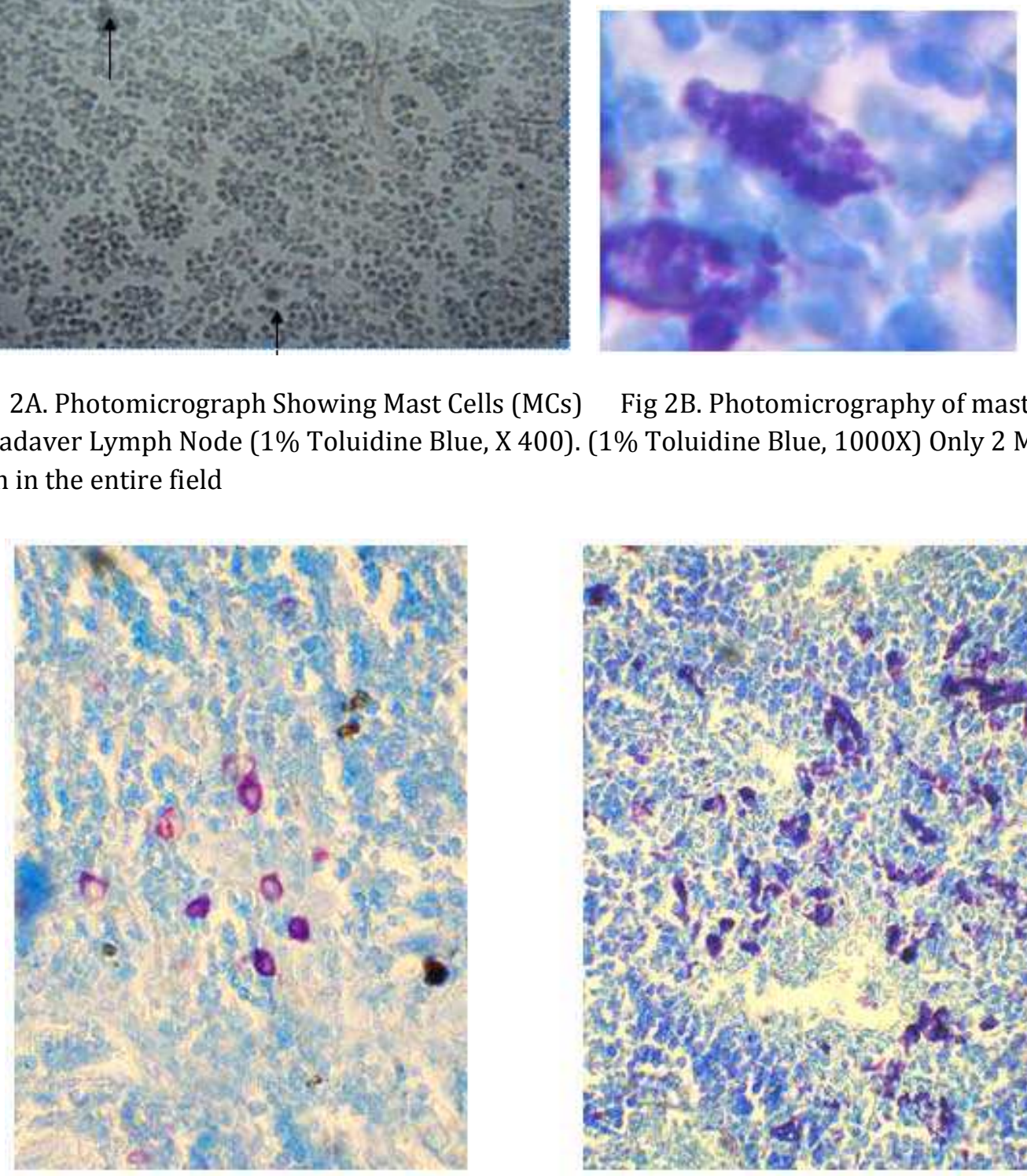

Fig 2B. Photomicrography of mast in Cadaver Lymph Node (1\% Toluidine Blue, X 400). (1\% Toluidine Blue, 1000X) Only 2 MCs are

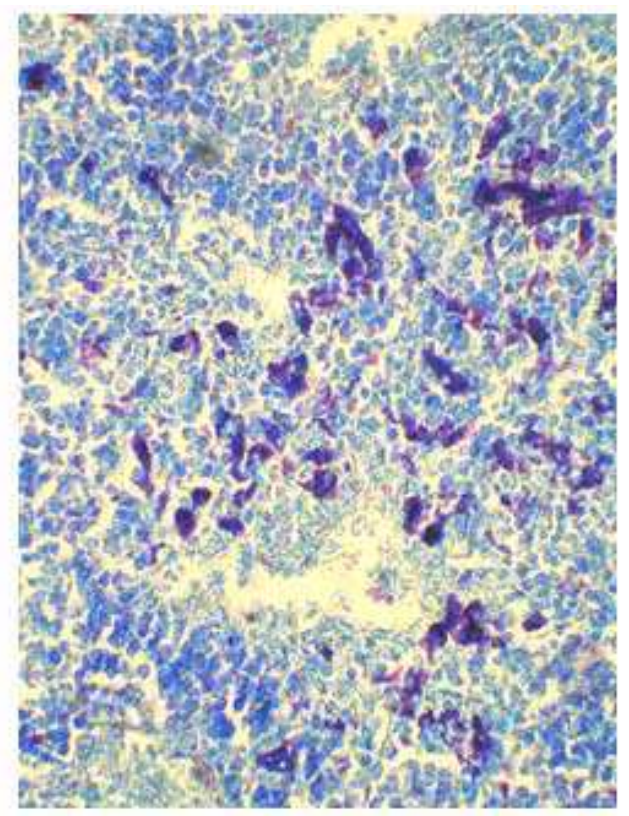

Fig. 3 A \& B. Photomicrographs showing marked increase of Mast Cells (MCs) in Follicular hyperplasia. (1\% Toluidine Blue, X 400). More MCs are seen in the field, they are between the follicles 

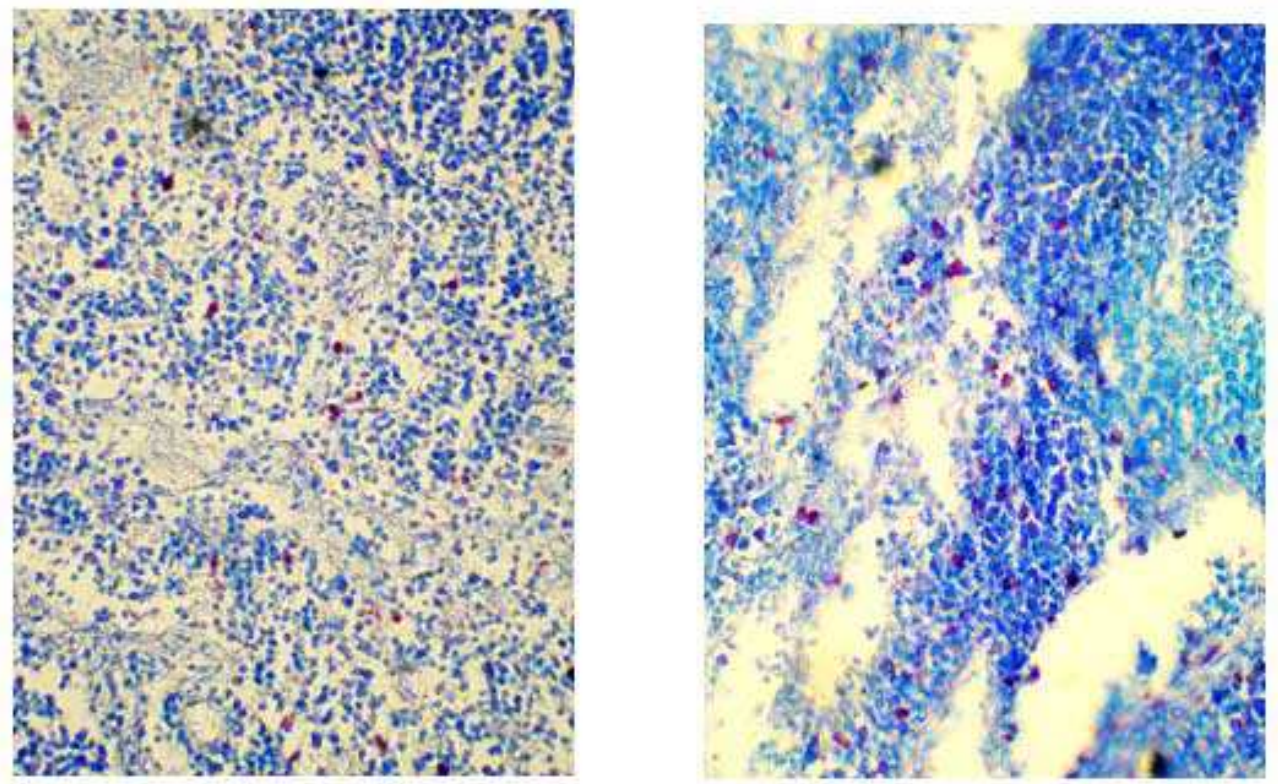

Fig. 4 A \& B. Photomicrograph showing marked increase in Mast Cells (MCs) in sinus histiocytosis. (1\% Toluidine Blue, X 400). Many MCs are seen in the field.

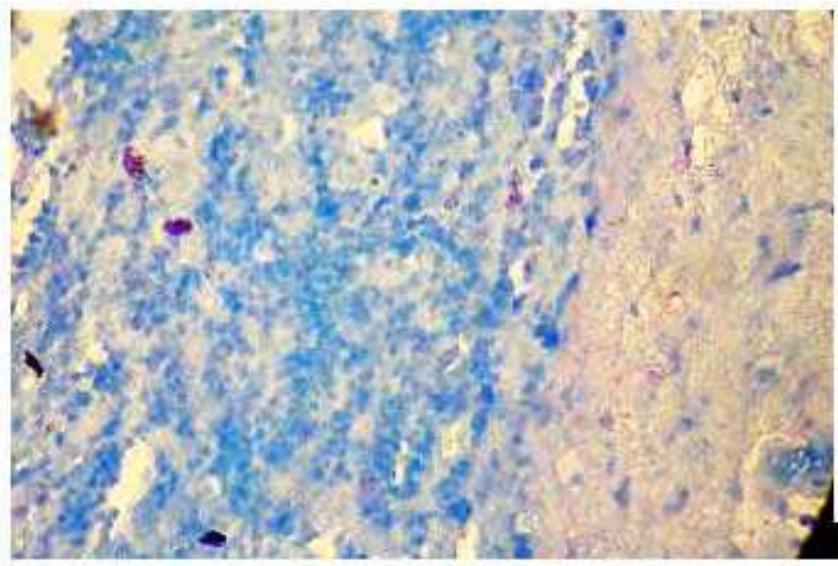

Fig. 5. Photomicrograph Showing decrease of MCs in Tuberculosis of Lymph Node (1\% Toluidine Blue, X 400). Only 2 MCs are seen in around the granuloma. No MCs with in the granuloma. 

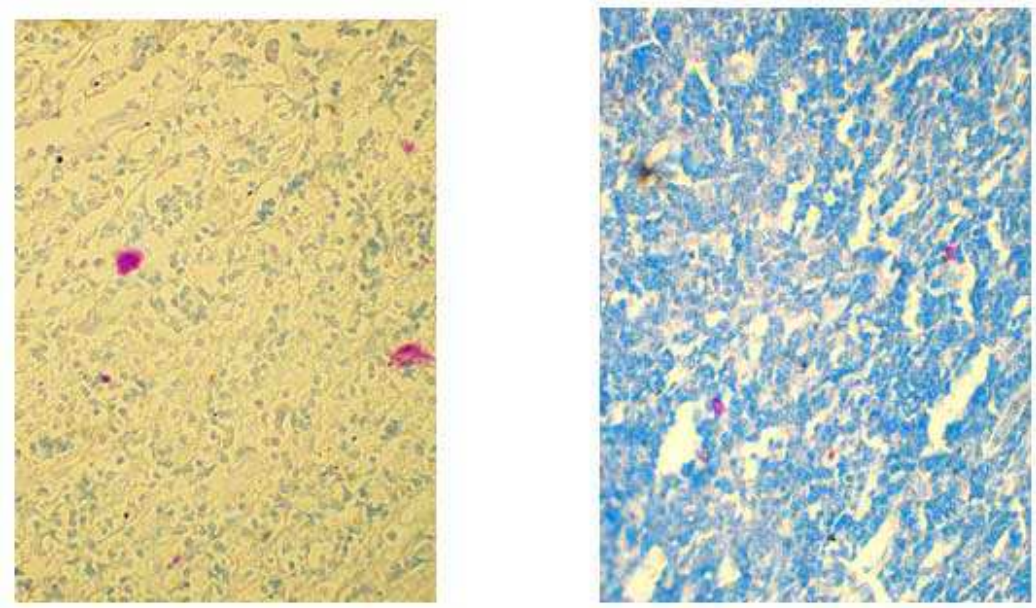

Fig. 6 A\& B. Photomicrograph Showing Mild increase in MCs in Non Hodgkin's Lymphoma (1\% Toluidine Blue, X 400). Only few MCs are seen in the entire field.

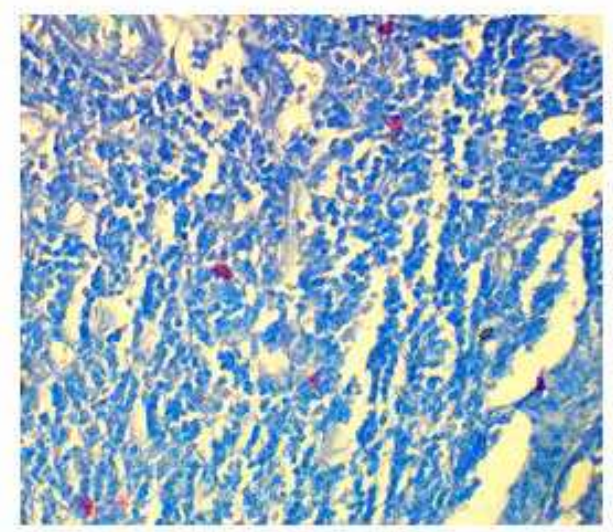

Fig. 7. Photomicrograph Showing Moderate increase of MCs in Hodgkin's Lymphoma. (1\% Toluidine Blue, X 400). Only few MCs are seen in the entire field.
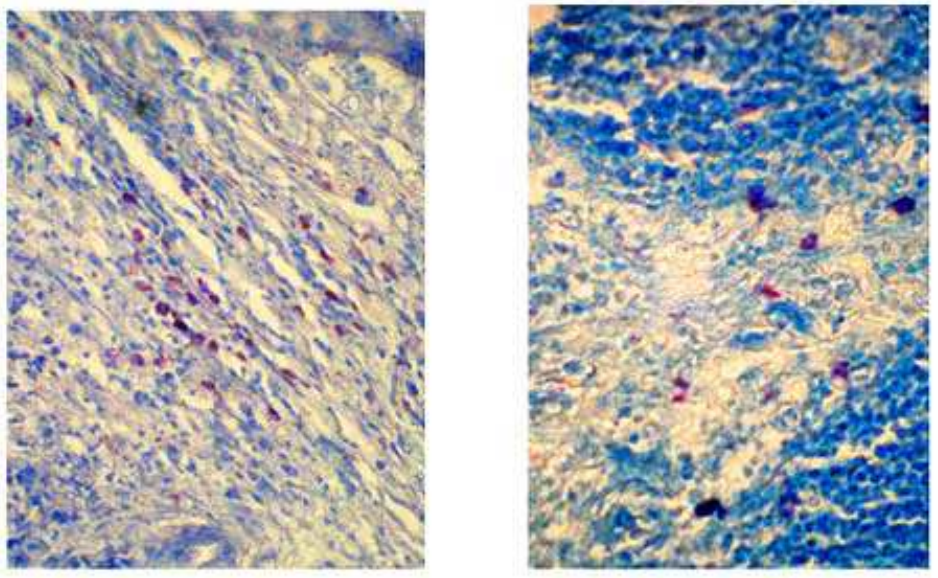

Fig. 8 A \& B. Photomicrograph Showing Moderate increase of MCs in Metastatic lymph node. (1\% Toluidine Blue, $\mathrm{X} 400)$. MCs are seen around the metastatic deposits. 


\section{ORIGINAL ARTICLE}

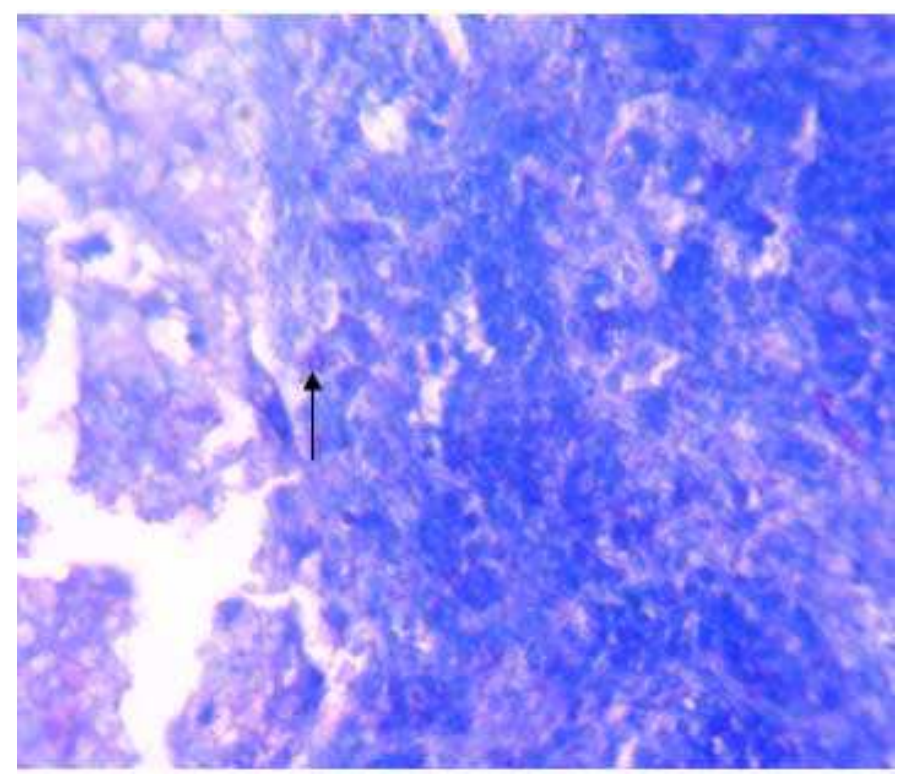

Fig. 9. Photomicrograph of Combined lesion. (1\% Toluidine Blue, X 400). Only few MCs are seen around metastasis but not around granuloma.

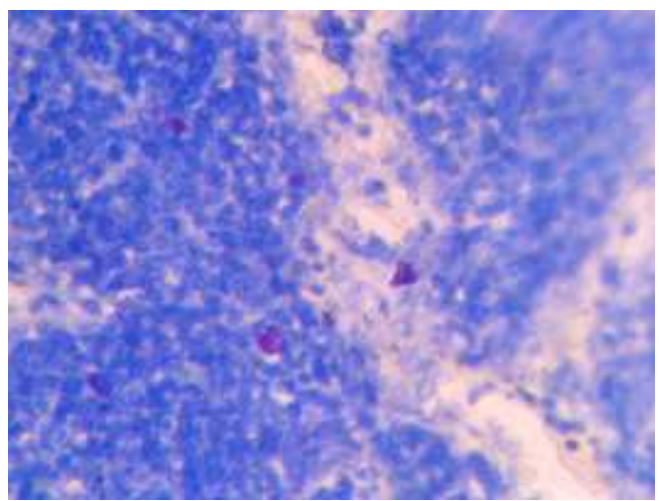

Fig. 10. Photomicrograph of Dermatopathic lymphadenitis. (1\% Toluidine Blue, X 400). 5 MCs are seen in the section. 